\title{
REVIEW
}

\section{Regulation of tissue-resident memory T cells by the Microbiota}

\author{
Abigail E. Overacre-Delgoffe ${ }^{1,2}$ and Timothy W. Hand (DD ${ }^{1,2 凶}$ \\ (c) The Author(s), under exclusive licence to Society for Mucosal Immunology 2022
}

\begin{abstract}
Resident memory T cells (Trms) predominantly reside within tissue and are critical for providing rapid protection against invasive viruses, fungi and bacteria. Given that tissues are heavily impacted and shaped by the microbiota, it stands to reason that Trms are also influenced by the microbiota that inhabits barrier sites. The influence of the microbiota is largely mediated by microbial production of metabolites which are crucial to the immune response to both viral infection and cancerous tumors. In addition to the effects of metabolites, antigens derived from the microbiota can activate $T$ cell responses. While microbiota-specific $T$ cells may assist in tissue repair, control of infection and anti-tumor immunity, the actual 'memory' potential of these cells remains unclear. Here, we hypothesize that memory responses to antigens from the microbiota must be 'licensed' by inflammatory signals activated by invasion of the host by microorganisms.
\end{abstract}

Mucosal Immunology (2022) 15:408-417; https://doi.org/10.1038/s41385-022-00491-1

\section{INTRODUCTION}

Immune memory, the ability of $\mathrm{B}$ and $\mathrm{T}$ cells to make antigenspecific recall responses to counteract reinfection, is the cardinal attribute of the adaptive immune response. The evolution of adaptive immune cells with rearranged, variable antigen receptors that can respond to an almost unlimited number of antigens, coincides with the acquisition of a complex intestinal microbiome. It has been theorized that the purpose of the immune memory is not only to protect the host against re-infection, but also to 'remember' benign interactions with the microbiome to prevent continuous and potentially damaging responses ${ }^{1}$. Accordingly, the development, maintenance, and function of memory lymphocytes is likely responsive to signals derived from the microbiota.

Memory $\mathrm{T}$ cells can be broadly divided into three main categories Central (Tcm), Effector (Tem) Memory cells that circulate through secondary lymphoid tissue and Tissue Resident memory $(\operatorname{Trm})^{2,3}$ that permanently reside in tissue. Tcm cells largely reside in secondary lymphoid tissue and are defined by the expression of surface proteins (CD62L, CCR7) and transcription factors (KLF2) that mediate that program. In contrast, Tem cells lack the expression of these surface molecules and traffic back and forth between the secondary lymphoid tissue and the peripheral blood/tissues. Tem and $\mathrm{Tcm}$ can interconvert in response to re-activation or the contraction of an immune response. In contrast, Trms reside permanently in the tissues and do not require reconstitution from the secondary lymphoid tissues, though this can occur under specific circumstances, such as re-infection ${ }^{3-5}$. Trms are important for protective immunity as they reside directly within the barrier tissue sites most commonly accessed by invasive microorganisms and can act immediately to prevent or limit infection ${ }^{6-8}$. While tissue-resident memory has been most thoroughly studied in $\mathrm{CD}^{+}$ $\mathrm{T}$ cells, it is also a property of $\mathrm{CD}^{+}{ }^{+} \mathrm{T}$ cells and perhaps even $\mathrm{B}$ cells ${ }^{9-11}$. In this review, we will focus on T cells.

Barrier surfaces are inhabited by diverse populations of bacteria, fungi, protists and viruses that together compose the microbiota $^{12}$. Metazoans have evolved in concert with a microbiota and as such the microbiota modulates multiple aspects of host physiology. For example, anaerobic intestinal bacteria are necessary for the digestion of complex carbohydrates and metabolites produced by that digestion are an important carbon source for the colonic epithelium. Microbiome-derived products and metabolites are also critical for the development and function of the immune system ${ }^{13}$. Environmental factors, most notably the diet, directly impact the composition of the microbiome, which in turn influences both the local immune response in adjacent host tissues and systemic immunity ${ }^{14,15}$. The microbiota affects both the innate and adaptive arms of the immune system and as such, is an important modifier of immunological memory.

Tissue resident memory T cells (Trms) are shaped by the tissue in which they reside. Since the microbiota is a dominant factor in shaping immunity at barrier surfaces, it follows that it also affects the Trm cells. The microbiota varies at different barrier tissue sites (small intestine, colon, mouth, skin, etc) ${ }^{16}$ and can differ enormously according to the condition of the tissue (infection, wounding, antibiotics, etc) ${ }^{17-20}$. Thus, Trms will be subject to microbiota-derived cues that differ according to the tissue and local environmental conditions. In addition, the microbiome also drives the development of microbiota-specific $T$ cell responses that are shaped by the type of microbe carrying the antigenic peptide, tissue location, and environmental context. Here we will review how the microbiota shapes $\mathrm{CD}^{+}$and $\mathrm{CD}^{+}{ }^{+} \mathrm{Trm}$ development, survival, and function.

\section{THE MICROBIOTA AND MICROBIOTA-DERIVED METABOLITES IN TRM DEVELOPMENT}

The development of Trms (and all other memory $\mathrm{T}$ cell subsets) begins when naïve $T$ cells are activated in the lymph nodes by dendritic cells carrying antigens from the surrounding tissue. Signals imparted on dendritic cells by the tissue from which they

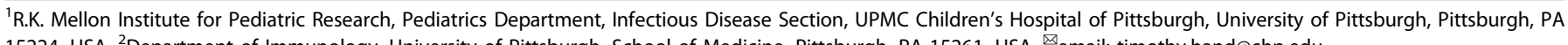
15224, USA. ${ }^{2}$ Department of Immunology, University of Pittsburgh, School of Medicine, Pittsburgh, PA 15261, USA. ${ }^{\circledR}$ email: timothy.hand@chp.edu 
are derived are critical to the differentiation of naïve $T$ cells to effector $\mathrm{T}$ cells and ultimately, tissue-resident memory $\mathrm{T}$ cells. $\mathrm{CD}^{+}$Trms predominantly develop from 'memory precursor' $\mathrm{CD}^{+} \mathrm{T}$ cells, though there is also a route for Trms to develop from $\mathrm{KLRG}^{+}{ }^{+}$terminal effectors ${ }^{\prime 21,22}$. Development of Trms is driven by inflammatory cytokines, such a IFNa and IL-12 and is directed by expression of transcription factors such as Blimp-1, Hobit and $\mathrm{Ahr}^{23}$. Upon activation, CD69 is upregulated transiently in T cells, but this signal is maintained in Trm cells ${ }^{24}$. CD69 expression antagonizes S1PR1 surface expression, thereby reducing $\mathrm{T}$ cell egress signals and results in tissue residency. In addition, $\mathrm{CD}^{+}$ Trms that reside at epithelial sites such as the skin, but not the intestine upregulate adhesion molecules (CD103), chemokine receptors (CXCR3, CXCR6) and downregulate lymphoid homing receptors (CCR7), aiding in their ability to remain tissueresident ${ }^{22,25}$. Once in the tissue, Trms continue to receive signals from their local environment, including cytokines (TGF $\beta)^{26-29}$ that are important for tissue retention and survival (IL-7 and IL$15)^{22,30,31}$. As we will discuss below, the microbiota can shape all of these aspects of Trm development and function at various tissue sites (Fig. 1).

Beyond any specific effects on Trms, the microbiota is important for the overall function and development of effector and memory $\mathrm{T}$ cells. Germ-free mice, that are propagated entirely without any microbiota, are predisposed to 'Type 2' adaptive immune responses that are characterized by CD4 $+\mathrm{T}$ cells and NKT cells that produce $\mathrm{IL}-4, \mathrm{IL}-5$ and $\mathrm{IL}-13^{32,33}$. Antiviral $\mathrm{CD} 8+\mathrm{T}$ cell responses are also affected in microbiota-depleted mice. Antibiotic depletion of the microbiota in mice leads to a reduction in the accumulation of virus-specific effector CD8 + T cells ${ }^{34,35}$. This reduction was dependent primarily on the absence of Gram positive bacteria which produce various TLR ligands and lead ultimately to the upregulation of IL- $1 \beta$ by APCs. Indeed, T cell numbers and viral protection could be restored by replicating the impact of the microbiome through direct TLR stimulation ${ }^{34,36,37}$. $\mathrm{CD} 8+\mathrm{T}$ cells from microbiota-depleted mice are not only reduced in number, but also display a dysfunctional phenotype, characterized by an increase in inhibitory receptors (PD-1, 2B4, CD160, and LAG3) and a reduction in cytokine production, especially IFN $\gamma$ and $\mathrm{TNFa}^{38}$. Microbiota depletion leads both to more severe disease in response to the initial infection and also results in reduced virusspecific serum IgM and IgG and a reduction in viral-specific $C D 8^{+}$ memory $\mathrm{T}$ cells, showing that the microbiota is required for optimal viral control ${ }^{35,39}$. This is a complex issue however, as depletion of the microbiota can reduce 'colonization resistance' to oral Listeria monocytogenes infection and thus increase the resultant intestinal infection and production of Trms ${ }^{40}$. Therefore, the absence of specific microorganisms within the microbiota, can affect $\mathrm{T}$ cell responses to infection. An example of this property are comparisons between wild and pet store mice and specific pathogen-free (SPF) that are used for most experiments to control for environmental variables. However, SPF mice are not always reliable representations of humans and one primary difference is reduced diversity and increased stability of the microbiome ${ }^{41}$. Laboratory mice are not devoid of a microbiota, but because they are continuously propagated in cages and do not freely interact with their environment and other animals, their microbiomes are generally less diverse and subject to significant 'cage effects', where lineages of mice can differ in their microbiome because of 'drift' that is driven by their provenance and not any underlying genotype/phenotype ${ }^{42}$. This overall lack of microbial diversity results in an altered immune system compared to mice a

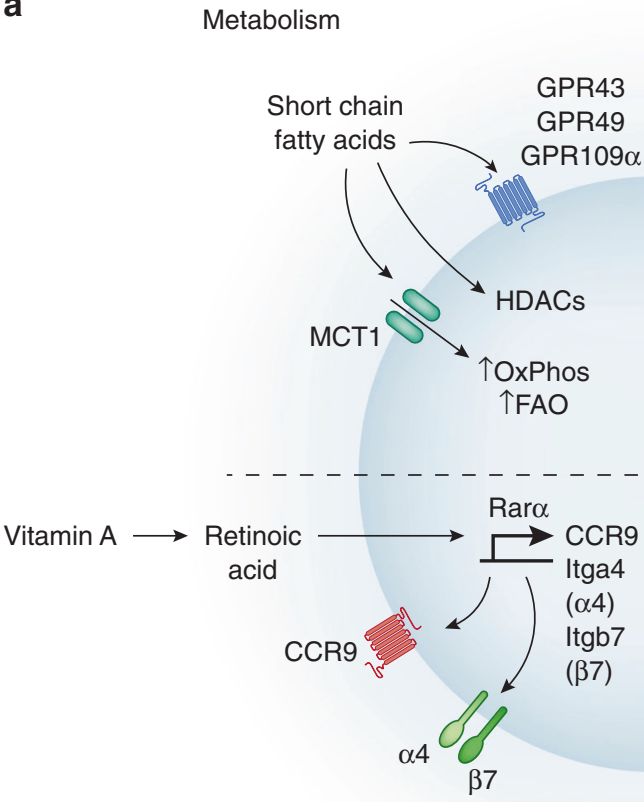

b d Protection against environmental toxins

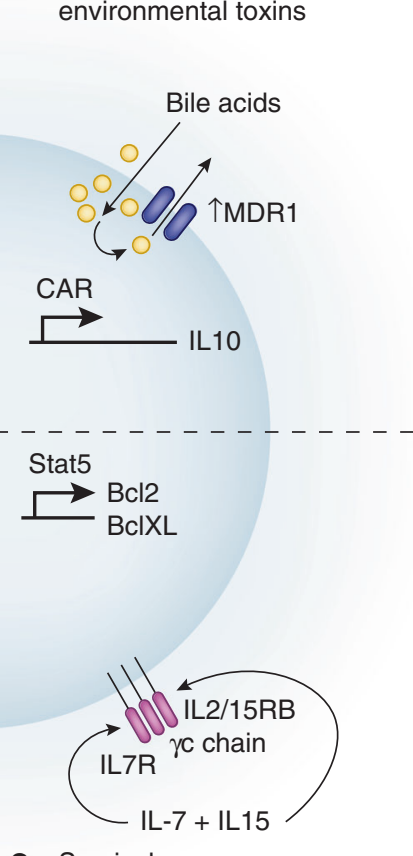

C Survival

Fig. 1 Tissue resident memory signals regulated by the microbiota. Trms reside in tissues and are directed by signals in their local environment. The microbiota is one of the dominant factors controlling the barrier tissue environment and microbiota-derived signals may be important for Trm survival. a Microbiota derived SCFAs direct T cell metabolism toward Oxidative Phosphorylation (OxPhos) and Fatty Acid Oxidation (FAO) that benefit long-term survival. b Microbiota controls the production of Retinoic Acid from Vitamin A, which via activation of the transcription factor Rar $\alpha$ activates expression of the chemokine receptor CCR9 and the integrin $\alpha 4 \beta 7$ which guide T cells back to the intestine. c Microbiota-induced IFN $\gamma$ and dendritic cell activation can increase IL-7 and IL-15 production, which activates anti-apoptotic genes (Bcl-2, Bcl-XL). d MDR1 and CAR protect T cells against bile acid induced toxicity allowing for survival in the small intestine and decrease inflammation via increasing IL-10 and decreasing TNF $\alpha$. 
410

propagated in the wild or in pet stores and most importantly, humans. Laboratory mice show a deficit in $\mathrm{CD}^{+}{ }^{+}$Trms compared to 'wild' mice or humans and possess a surplus of naïve $C D 8^{+}$ $\mathrm{T}_{\text {cells }}{ }^{43}$. In addition, laboratory mice show a reduction in $\mathrm{CD}^{+} \mathrm{T}$ cell infiltration into mucosal barrier sites, such as the reproductive tract or salivary gland, both of which are readily infiltrated in petstore mice and humans ${ }^{43}$. Fascinatingly, these immune defects can be restored by co-housing laboratory mice with 'wild' mice. The exact microorganisms that drive the shifts between SPF mice co-housed with pet store mice or mice carrying a wild microbiome have not comprehensively described, but host infecting viruses that would not typically considered part of the microbiome likely have a dominant effect ${ }^{43}$. However, the bacterial microbiota of wild mice also differs substantially from SPF mice and likely is also an important modifier of the $T$ cell response ${ }^{41,44}$. 'Wilding' of laboratory mice has also revealed an important role for fungi in inducing Th17 immune cells ${ }^{44-47}$. Together these results demonstrate that the microbiota can directly impact long-term $\mathrm{T}$ cell responses at mucosal barriers and that modification of the composition of the microbiota may be a mechanism to improve $T$ cell responses and augment vaccines.

\section{Microbial derived or modified metabolites as modulators of Trms}

The metabolites produced by the microbial digestion of food can impact the immune system within the gut and beyond. For example, short-chain fatty acids (SCFAs; acetate, propionate or butyrate), which are primarily derived from the breakdown of dietary fiber by the gut microbiome, contribute to and stabilize the gut-resident regulatory $T$ cells and reduce inflammatory innate immune cells ${ }^{48-52}$. In addition to regulatory $T$ cells, SCFAs have also been associated with increased $\mathrm{CD} 8^{+}$memory $\mathrm{T}$ cell survival and function. SCFAs have many cellular targets and it is likely that they affect memory $T$ cell development and homeostasis indirectly via effects on innate immune cells and Treg cells, which regulate memory cell differentiation through cytokine expression ${ }^{51,53}$. CD4 and CD8 T cells also be directly affected by SCFAs as they express multiple SCFA receptors (GPR41, GPR43 and GPR109a) and transporters (MCT1). For example, acetate, can be directly taken up by $\mathrm{CD}^{+} \mathrm{T}$ cells and boost glycolytic activity through an increase in acetyl-coA, which supports immediate $\mathrm{CD} 8^{+}$effector functions after infection (such as Listeria) and thus an increased $\mathrm{CD}^{+}$memory $\mathrm{T}$ cell pool ${ }^{54}$. High fiber diets are associated with an increase in Bacteroidetes a reduction in Firmicutes, an increase in SCFA production, especially butyrate and reduced severity in a mouse influenza infection model ${ }^{52}$. Increases in SCFAs mediated by the high fiber diet supported an increase in IL-10 and IL-4 production in the lung, and importantly, a high fiber diet led to an increase in virus-specific $\mathrm{CD}^{+} \mathrm{T}$ cells and a dampening of inflammatory monocytes ${ }^{52,54}$. With a high fiber diet, flu-specific $\mathrm{CD}^{+} \mathrm{T}$ cells not only produce more cytokine (IFN $\gamma$, TNFa) during primary infection but are also more metabolically robust through elevated fatty acid oxidation ${ }^{52}$. SCFAs also promote the development of long-term memory. For example, butyrate, increased the uptake of fatty acids and oxidative phosphorylation in $\mathrm{CD}^{+}$ memory $\mathrm{T}_{\text {cells }}{ }^{55}$, which supports memory cell survival ${ }^{56}$. SCFAs also promotes IL-10 production, that is critical to the development of memory CD8 T cells ${ }^{57,58}$. Beyond SCFAs, other metabolites that are modified by the microbiota are also important for tissueresident $T$ cell function. Retinoic acid (RA) is a metabolite of Vitamin A whose production by intestinal epithelial cells is regulated by spore-forming Clostridia ${ }^{59}$. Conversely, the specific bacteria within the microbiota (Segmented filamentous bacteria, Bacillus cereus, Bifidobacteria bifidum) can produce RA from Vitamin $A$, independent of host effects ${ }^{60}$. The presence of RA is critical for robust intestinal $T$ cell responses (and thus intestinal Trms) to infection because it is necessary for the development of $C D 11 b+C D 103+D C s$ in the intestine and for full activation of
$T$ cells via the $T C R^{61,62}$. Also, RA is necessary for the expression of the chemokine receptor CCR9 and the integrin $a 4 \beta 7$, two surface proteins necessary for the traffic of $T$ cells and therefore Trm development, in the small intestine and colon ${ }^{63,64}$. Bile acids, which are produced by the liver to aid in the digestion of fat, are also modified by the microbiota and have been shown to modulate intestinal T cells. For example, microbiota-modified bile acids are critical for the development of a subset of FOXP3 + Tregs that co-express the transcription factor ROR $\mathrm{T}^{65}$. Additionally, bile acids can directly modulate effector/memory $T$ cell homeostasis in the intestine. Activated CD4 $+\mathrm{T}$ cells in the intestine up-regulate the expression of the nuclear bile acid receptor CAR and as a result the Multi drug resistance transporter (MDR1, Abcb1a) ${ }^{66,67}$. Expression of CAR/MDR1 by CD4 + T cells is important to prevent bile acid toxicity, but also for the expression of IL-10 and the regulation of TNFa production, which together reduces intestinal inflammation ${ }^{66,67}$. Finally, the microbiota can be important for the production of the cytokines that mediate TRM survival: IL-7 and IL15. Experiments using IL-7 reporter mice have revealed that high levels of IL-7 are expressed in the intestine ${ }^{68}$. Intestinal IL-7 expression was induced by microbiota-dependent induction of IFNy which might explain why anti-viral $\mathrm{T}$ cell responses are so subdued in mice where the microbiota has been depleted by antibiotics $^{68,69}$. The microbiota-dependent expression of IL-7 might be particularly important for intestinal Trms since their survival has been shown to be independent of signals from IL$15^{70}$. IL-15 expression could also be affected by the microbiota. For instance, IL-15 and an altered composition of the microbiota have both been associated with Celiac disease and Inflammatory Bowel Disease (IBD) ${ }^{71,72}$. Indeed, NOD2, increases IL-15 expression in the intestine through sensing of the microbiota and single nucleotide polymorphisms in the Nod2 gene have been associated with $\mathrm{IBD}^{73}$. Altogether, these studies suggest that microbial metabolites have both direct and indirect impacts on Trm cell differentiation, function, and survival in tissues.

\section{The microbiota shapes the $\mathbf{T}$ cell response to cancer}

Activating the immune system to eradicate cancerous cells has revolutionized cancer therapy. Most immunotherapy approaches rely on activating or re-activating $T$ cells to kill tumor cells. While still a nascent area of research, tumor-resident Trm cells are an important target of immunotherapy approaches, and accordingly, the composition of the microbiota is important for therapeutic success ${ }^{74-80}$. Indeed, select gut bacterial species have been associated with better prognosis in melanoma patients and specifically, a better response to immunotherapies like antiPD1antibodies ${ }^{81-84}$. While the exact mechanism by which these bacteria provide a benefit is still unclear, increased tumor infiltration by $\mathrm{CD}^{+} \mathrm{T}$ cells and a reduction of Tregs within the tumor microenvironment have been associated with specific members of the microbiota. One potential mechanism by which the microbiota may benefit tumor immunotherapy is via the provision of metabolites. For example, a collection of eleven human members of the microbiota have been demonstrated to improve anti-tumor immunity, likely by shifting the metabolism of the microbiota ${ }^{85}$. Similarly, inosine derived from intestinal populations of Bifidobacteria, Lactobacillus, and Olsenella has been associated with increased numbers $\mathrm{CD} 8+\mathrm{IFN} \gamma+\mathrm{T}$ cells and control over tumor growth ${ }^{86}$.

$T$ cell responses raised against antigens derived from microbes, including bacteria within the microbiota, can also contribute to anti-tumor immunity. While tumor-specific T cells are undoubtedly critical to anti-tumor immunotherapy, a large proportion of tumorinfiltrating $\mathrm{CD}^{+}{ }^{+} \mathrm{T}$ cells are not specific to the tumor, but rather are 'bystander' $T$ cells that can be specific to microbes ${ }^{87,88}$. For example, $\mathrm{CD}^{+} \mathrm{T}$ cells activated by repeated bacterial and viral infections that traffic to tumors can contribute to anti-tumor immunity ${ }^{89}$. Virus-specific T cells can also be 'boosted' for better 
anti-tumor immunity through direct tumoral injection of viral peptides ${ }^{90}$. Enhanced anti-tumor immunity after a 'peptide boost' is associated with activation of dendritic cells and NK cells, leading to increased recruitment of $T$ cells. This response can unleash an effective immune response against the tumor after anti-PDL1 in otherwise resistant tumors and suggests that $T$ cells specific to viruses can be leveraged to enhance the anti-tumor immunity ${ }^{90}$.

Antigen-driven interactions with less infectious microorganisms that are found within the microbiota might also contribute to the antitumor immunity. The 'wild' mouse microbiome is associated with improved immune responses to colorectal cancer ${ }^{44}$. This response can be transferred to laboratory mice through a gavage of the 'wild' microbiome and is associated with an increase in the relative abundance of Proteobacteria (Helicobacter spp.), a decrease in Firmicutes and reduced colonic inflammation ${ }^{44}$. In concert with these findings, our group has shown that colonization of SPF mice with Helicobacter hepaticus is sufficient to provide long-term control over colorectal cancer. Protection provided by $\mathrm{H}$. hepaticus colonization required the development of Helicobacter-specific $\mathrm{T}$ Follicular Helper T cells (TFH) and Tertiary Lymphoid Structures (TLS) in and around the tumor. Together the increase in microbiota-driven TFH and TLS led to greater invasion of the tumor with cytotoxic T cells and NK cells ${ }^{91}$. However, not all strains of Helicobacter spp. may have this affect as other configurations of the microbiota containing large amounts of this taxa have been associated with failure of the CD8 + anti-tumor response ${ }^{92}$. In addition, this property is not strictly limited to Helicobacter, since a member of the Bacteroides phylum Odoribacter splanchnicus, also controls colorectal cancer via the induction of Th17 T cells ${ }^{93}$. Together these studies support the notion that leveraging the microbiota and microbe-specific memory $T$ cells could be a useful strategy to improve the efficacy of anti-tumor imunotherapy. In the future, it will be important to define the members of the microbiota that are best associated with improved treatment outcomes and to define the distinct microbiota compositions necessary to augment immunotherapy against different tumor types.

In addition to the effects of relatively distant microbiotas of barrier tissue sites, the tumor itself can harbor its own microbiome. Many cancer types, including breast, bone, pancreas, ovarian, lung, melanoma, and colorectal cancer harbor 'tumor microbiotas', which are typically dominated by anaerobic bacteria ${ }^{94-96}$. Though how exactly anaerobic bacteria traffic through the body to tumors is unclear, once there anaerobic bacteria can thrive in the hypoxic environment at the center of many tumors and can impact tumor growth $^{94-96}$. The type of tumor and location has a great impact on the bacteria present, with breast cancer harboring the most diverse microbiome, consisting of S. infantis, L. iners, and F. nucleatum ${ }^{97,98}$. In contrast, melanoma is far more restricted in microbiota diversity and is predominantly composed of P. marcusii and S. aureus ${ }^{97}$. However, other factors such as lifestyle can impact the tumor microbiome as well. In lung cancer, smokers show an increase in Acetobacteraceae, Rhodospirillales, Roseomonas, and Alcaligenes taxa compared to patients who have never smoked ${ }^{97,99}$. Perhaps most interestingly, melanoma patients that respond favorably to treatment with anti-PD1 show a distinct tumor microbiome, with an increase in Clostridia, Mycobacteria, and Novosphingoblum and a somewhat surprising reduction in Bifidobacteria given that this taxon has been associated with positively associated with tumor immunotherapy success in mouse models ${ }^{97}$. It is important to mention that the immune microbiota can also contribute to carcinogenesis and tumor growth, such as in liver cancer, pancreatic cancer and colon cancer ${ }^{100-104}$. In colon cancer, bacteria can contribute directly to tumorigenesis via damaging the DNA (pks $+E$. coli) and also by inducing inflammatory STAT3 activating cytokines from $T$ cells that can aid tumor growth and suppress antitumor immune responses (Fusobacteria, enterotoxigenic Bacteroides fragilis) ${ }^{105-107}$. It will be of great interest to learn further about the potential bacterial functionality, characteristics, or metabolites of tumor resident bacteria that either drive carcinogenesis or increase response to immunotherapies in hopes of developing novel microbial-based therapeutics.

\section{MICROBIOTA-SPECIFIC T CELL RESPONSES}

There is more diversity in the microbiota between different barrier tissue sites within an individual than there is diversity between different individuals at the same site ${ }^{16}$. To put more simply, the average person's intestinal microbiota looks more like their neighbor's intestinal microbiota than it does their own skin or mouth microbiota. This is evidence that various microbiotas are not random assemblages of whatever happens to land on a particular barrier site, but instead that the host is shaping which microorganisms can inhabit a given barrier tissue and the bacteria are also colonizing according to the environmental conditions. Within tissue-specific microbial communities there is also heterogeneity. For example, bacterial communities within the mammalian intestine often contain five or more different phyla and dozens of individual isolates within those phyla, each of which possess diverse genomes, structures and behavioral strategies to survive host colonization. The various members of the microbiota compete for resources within a constantly changing environment and the composition of the microbiota is not fixed. In response to microbiota heterogeneity, anti-microbiota $T$ cell responses are tailored according to the tissue environment. This phenomenon is best demonstrated by comparing the immune responses of the adult skin, intestine, and mouth.

\section{Intestine-resident microbiota-specific $\mathbf{T}$ cells}

The intestine contains the densest and most rich microbiota and the number of bacteria and their diversity generally increases from the duodenum to the rectum. Given this diversity, it is perhaps unsurprising that there is substantial diversity in the $T$ cell responses induced in the intestine. CD4 $+\mathrm{T}$ cells specific to bacterial members of the microbiota have been found to differentiate into Th1, Th17, T Follicular Helper (TFH), and regulatory $T$ cell (Treg) states ${ }^{108}$. In line with their diverse differentiation states, microbiota-specific T cells have been shown to perform a variety of important functions in the intestine, including limiting bacterial mucus colonization via the induction of anti-microbial peptides and the increase of IgA production and secretion ${ }^{109,110}$. Which of the various T cell differentiation states is induced in microbiota-specific $T$ cells depends upon both the biology of the inducing bacteria and the specific site along the intestine where the microbe resides. One property that is shared by all of the intestinal bacteria that have been demonstrated to induce 'spontaneous' immune responses is attachment or interaction with the intestinal epithelium/mucus layer ${ }^{11-119}$. For example, Segmented Filamentous Bacteria (SFB), Akkermansia muciniphilia, Mucispirillum schaedleri and $H$. hepaticus either directly adhere to the intestinal epithelium or live within the inner mucus layer, while Bacteroides thetaiotaomicron secretes outer membrane vesicles that can be absorbed by the host ${ }^{119}$. In contrast, bacteria that lack the ability to invade the mucus and epithelial surface require a breakdown of the intestinal barrier for recognition by host $T$ cells ${ }^{113,120}$. Despite the shared property of epithelial association, the immune responses induced by each of these organisms at steady state is very different (Fig. 2), where SFB induces predominantly Th17 responses but other bacterial taxa $(A$. muciniphilia, $H$. hepaticus, M. schaedleri, and the 'CBir' Lachnospiraceae isolate) induce varying mixtures of TFH and Tregs. Undoubtedly, biological attributes of each of these bacteria are partially responsible for the differences in the induction of $T$ cell response but where along the intestine that a particular bacteria colonizes is also important. Each part of the intestine drains to a different $L N$ within the mesenteric lymph node (LN) string and 


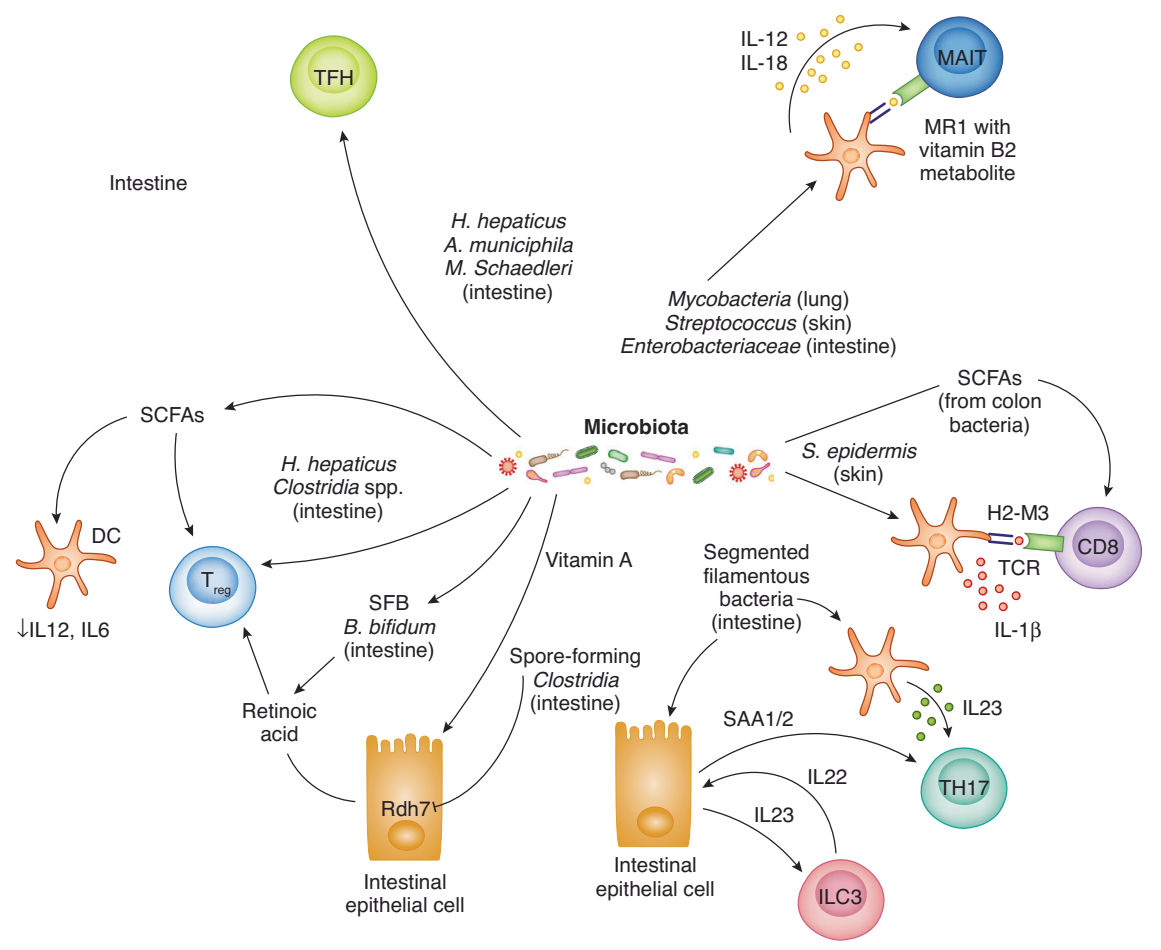

Fig. 2 Various members of the microbiota induce heterogeneous $\mathbf{T}$ cell responses. At different barrier tissue sites antigens derived from the microbiota can induce microbiota-specific $T$ cell responses. The differentiation state of microbiota-specific $T$ cells differs according to the nature of the host/microbe interaction, the tissue environment, and the type and magnitude of the innate immune response that is induced. Microbiota-derived metabolites also regulate effector/memory T cells directly via receptors on T cells and indirectly via modulation cytokine expression by antigen-presenting and epithelial cells. While microbiota-specific MHC class II restricted CD4 T cells (Treg, TFH, TH17) are the best understood, CD8 T cells and MAIT cells are specific to microbiota-derived peptides and Vitamin B2 metabolites expressed on nonclassical MHC class I molecules (H2-M3, MR1) have also been described. Where each bacteria predominantly resides on the host is described in parentheses.

each node has a different predisposition to various $\mathrm{T}$ cell states $^{121,122}$. In a broad sense, mucus resident/epithelium adherent bacteria, such as SFB in the small intestine drive responses that are dominated by Th17 T cells, with a minor population of Th1 cells ${ }^{112,123}$. Conversely bacteria that inhabit a similar mucosal niche in the colon ( $H$. hepaticus, $A$. muciniphilia etc.) induce responses that are mixed between Treg and $\mathrm{TFH}^{116,117,124}$. Within the small intestine, there are also differences between bacteria that live in the proximal versus the distal small intestine. The LN that drains the duodenum is more skewed towards the induction of Tregs while in contrast, the ileal draining $L N$, is more skewed to the induction of Th17 $\mathrm{T}$ cells ${ }^{121}$. The reason for this is that presumably the duodenum-draining $L N$ is more important for inducing tolerance to food, while the ileum, which is more anaerobic and less acidic, is home to more mucus-resident bacteria which must be contained to prevent inflammation. These differences also extend beyond the bacterial microbiome to protists where Tritrichomonas spp. colonization of the colon induces Th1 immune responses, whereas the same or similar protists colonizing the small intestine induce ILC2 activation and a more type 2 skewed response ${ }^{125-127}$.

In the intestine the majority of the anti-microbiota $T$ cell responses that have been described are CD4 + Helper T cells. It is possible that the relevant intestinal conditions/microorganisms where robust anti-microbiota $\mathrm{CD} 8+\mathrm{T}$ cell responses are evident have not been identified. Alternatively, MHC class I restricted CD8 $+\mathrm{T}$ cell responses may compose a relatively minor population because benign members of the microbiota rarely invade the host cytoplasm or induce apoptosis and are thus poor initiators of MHC class I cross-presentation by antigen-presenting cells. There are effects of the intestinal microbiota on systemic CD8 $T$ cell differentiation and function and though rare, $C D 8+T$ cells that are cross-reactive to microbiome-derived peptides have been observed $^{85,128}$. There is also evidence of CD8 T cells that are specific to bacteriophages carried in microbiota-derived bacteria $^{129}$. Intestinal resident CD8 T cell populations that possess either inflammatory (TNFa) or regulatory (IL-26) transcriptional modules are associated with Ulcerative colitis, so anti-microbiota CD8 $\mathrm{T}$ cell responses are potentially very important ${ }^{130}$ and more research in this area is needed.

\section{Microbiota-specific $\mathbf{T}$ cells outside the intestine}

In the skin, the microbiome-specific T cell population is comprised of both $\mathrm{CD} 8+$ and $\mathrm{CD} 4+\mathrm{T}$ cells. Colonization of the skin of rodents with Staphylococcus epidermidis induces CD4 + Tregs, CD4+Th1 cells and IL-17-expressing CD4+ and CD8+ $T$ cells ${ }^{131,132}$ (Fig. 2). The antigens that drive the $C D 8+T$ cell response to $S$. epidermidis have been identified and are formylated peptides presented upon H2-M3 MHC class I like molecules ${ }^{133}$. Unlike $\mathrm{CD} 8+\mathrm{T}$ cells raised in response to viral infections, microbiota-specific $\mathrm{T}$ cells in the skin do not express gene modules associated with cytolytic killing of infected cells and instead express functions associated with tissue repair and alarmin expression, which can help close wounds and control fungal infections $^{131,134,135}$. These dual functions are reflective of the primary function of the skin, to act as a barrier for the internal organs to the environment. One interesting aspect of skin-resident microbiota-specific CD8 + T cells is the co-expression of transcription factors (GATA-3 and RORYT) and gene modules (Th2 and Th17) that define distinct developmental lineages of Innate Lymphoid cells ${ }^{134}$. Similar to the intestine, the microbiome of the skin varies from site to site (sebaceous, dry, and damp) and it will be interesting to determine whether the T cell response in the skin also varies according to these changes ${ }^{136}$. 
The female reproductive tract (FRT) is also colonized by a microbiome, but here in stark contrast to the intestine, diversity is not associated with health, and many women are colonized with only one or two isolates of Lactobacilli ${ }^{137}$. To our knowledge, it has not been shown whether the vaginal microbiota induces antigenspecific T cells, but Lactobacilli tend to be relatively immunologically inert or even immunoregulatory, so T cell responses may be relatively muted in the $\mathrm{FRT}^{138,139}$.

In contrast to the epithelial layer of the intestine, the mouth is dominated by $\mathrm{CD} 4+\mathrm{T}$ cells rather than $\mathrm{CD} 8+\mathrm{T}$ cells. In the tongue, TCRa $\beta+C D 4+I L-17 A+T$ cells are responsive to the microbiome and can provide antigen-independent protection against subsequent Candida infection ${ }^{140}$. Whether these cells are specific to antigens derived from the mouth microbiota is not clear, but an interesting hypothesis is that these tongue-resident $\mathrm{CD} 4+\mathrm{T}$ cells are induced by the microbiome to provide heterologous protection against infection. In contrast, the $\mathrm{TCRa} \beta+\mathrm{CD} 4+\mathrm{IL}-17 \mathrm{~A}+\mathrm{T}$ cells residing in the gingiva develop independently of the microbiota and instead respond to the act of mastication $^{141}$. It is surprising to see such diversity in $T$ cell responses at physically connected oral surfaces and it will be exciting to learn the mechanisms by which these cells develop and traffic to their respective sites.

Development and differentiation of microbiota-specific $\mathbf{T}$ cells The anti-microbiota $T$ cell response is not just shaped by where the bacteria colonize but also when the bacteria colonize during development. While still a very contentious area of research ${ }^{142}$, the process of microbiota colonization and therefore antimicrobiota $\mathrm{T}$ cell responses may begin in utero, where some studies have shown that fetuses have a small population of bacteria on their barrier surfaces, particularly the intestine ${ }^{143,144}$. In accord, in human fetuses, the intestine is home to a relatively robust population of effector/memory $T$ cells some of which are phenotypically similar to TRMs and specific to bacteria present in the 'fetal microbiota'143,145. However, caution should be taken in interpreting the paired discoveries of the fetal microbiota and $T$ cell memory development, since the re-derivation of germ-free animals would argue against the presence of viable bacteria in the final stages of pregnancy. Further, the long-term implications of the population of the intestine with microbiota and TRMs prior to delivery are unclear since they will soon be overwhelmed by colonization of the microbiota post birth. Independent of the possibility of a fetal microbiota, maternal infection can pre-dispose infants to increased CD4 + IL-17 + T cell responses in the intestine after delivery and these $T$ cells protect against intestinal infection, so there is evidence of in utero effects on T cell immunity postdelivery ${ }^{146}$. The colonization of infant intestines by the microbiota post-delivery is a regulated process whereby both maternal (Human Milk Oligosaccharides and Immunoglobulin A from breast milk) and host inputs combine to protect the infant from damaging inflammatory micoorganisms and shape the microbiome to support health ${ }^{147}$. In mice prior to weaning, the intestinal resident $\mathrm{CD} 4+\mathrm{T}$ cell response is subdued with the majority of intestinal and mesenteric lymph node CD4 $+\mathrm{T}$ cells being unactivated ${ }^{148}$. Both $\operatorname{lgA}$ from breast milk and $\operatorname{lgG}$ transferred via the placenta are important for the maintenance of naïve $T$ cells in the neonatal mesenteric lymph nodes and thus the maternal antibody response is critical in shaping Trms in the early stages of immune development post-birth ${ }^{148,149}$.

In the intestine, Tregs can be generally subdivided based upon their expression of the transcription factor RORYT and the surface protein Neuropilin-1 (Nrp1), where microbiota-specific Tregs are RORYT + Nrp1-, self-antigen specific Tregs are RORYT-Nrp1+ and food antigen-specific Tregs are negative for both markers ${ }^{150-152}$. A wide variety of bacteria appear to be capable of inducing RORYT + Tregs ${ }^{151,153}$, and the induction and accumulation of RORYT + Tregs begins at weaning in response to the expansion of microbiota diversity that occurs at this time ${ }^{154}$. Importantly, if RORYT + Nrp1-Tregs are not induced at the time of weaning they cannot be restored by subsequent bacterial colonization, which makes the host more susceptible to autoinflammatory disorders such as IBD and allergy ${ }^{154}$. The frequency of RORYT + Nrp1-Tregs is controlled maternally through the provision of $\lg A$ in the breast milk through multiple generations ${ }^{155}$. Similarly, in the skin, early colonization of mouse pups predominantly induces Tregs which can assist long-term in preventing exacerbation of skin inflammation by the skin microbiota ${ }^{132}$. Taken together, there seems to be a predisposition of early life anti-microbiota $T$ cell responses toward regulation and tolerance that is mediated by a combination of linked antibody and Treg responses that limit access and activation against microbiota-derived antigens experienced early in life. Given the substantial shifts in the composition of the microbiota that occurs during this time, such responses make intuitive sense as a mechanism to prevent autoinflammation. It will be interesting to determine if such 'openness' is punished by microorganisms that use this window to gain a foothold when otherwise they would induce a protective inflammatory immune response. One such example of this phenomena could be pediatric malnutrition, which allows for increased colonization by inflammatory isolates of Proteobacteria ${ }^{156,157}$ and in mouse models leads to both considerable immune cell infiltration and pathology and as a result the induction of RORYT + Nrp1- Tregs that inhibit effector $\mathrm{CD} 4+\mathrm{T}$ cell responses in the small intestine ${ }^{158}$.

\section{Do microbiota-specific T cells form memory?}

Putting all these findings together, it is clear that a subset of bacteria, protists, and fungi at multiple-barrier tissue sites induce $T$ cell responses. What has been less clear is whether these T cells are forming true memory $T$ cell responses, defined by the ability to survive for long periods of time without cognate antigen restimulation while maintaining the ability to reconstitute secondary responses to provide rapid protection. Most microbiota-specific $T$ cell responses that have been described to date are CD4 + T cells, which even when responding to infections do not possess the vast memory potential of CD8 + T cells ${ }^{159,160}$, so even if CD4 + microbiota-specific T cells do survive to form memory the expectation is that they would diminish over time. Indeed long-lived microbiota-specific CD4 + T cells that dwindle over time have been demonstrated under conditions where infection and physical breakdown of the intestine lead to systemic translocation of the microbiota from barrier surfaces, though in these experiments the antigen is likely continuously present within the intestinal microbiota ${ }^{120}$. In support of the concept that access to antigen could be important microbiota-specific CD4+ $\mathrm{T}$ cells, such cells are significantly increased in patients with Inflammatory Bowel Disease compared to healthy controls whose intestinal barriers are presumably more consistently intact ${ }^{161}$. Conversely, in some circumstances memory CD4 $+\mathrm{T}$ cells can survive without antigens as experiments in mice show that colitogenic CD4 + T cells can survive after transfer into lymphopenic germ-free mice and drive colitis after subsequent colonization with a microbial flora ${ }^{162}$. In contrast to the increase in CD4 + T cell responses, patients with Crohn's Disease (CD) or Ulcerative Colitis (UC) present with lower numbers of $C D 8^{+} \mathrm{Trms}^{130,163}$. Trms isolated from CD or UC patients expressed a number of regulatory markers including IL-10, IL-26, and CD39, suggesting that they may aid in maintaining homeostasis and reducing inflammation, and that in diseases such as Crohn's or Ulcerative Colitis, an overall reduction in Trms contributes to inflammatory phenotypes, perhaps by allowing systemic immune responses against the microbiota $^{130,164}$

Outside of their effects on inflammatory disease, it has been hypothesized that microbiota-specific Trm cells might act as a heterologous defense system, where infection could lead to their 
re-activation and induction of a generic immune response ${ }^{120}$. Heterologous protection has been demonstrated in principle in the intestine where $\gamma \delta$ T cells responding to infection with the Gram positive bacteria Listeria monocytogenes can provide protection against Gram negative Salmonella infections ${ }^{165}$. Additionally, microbiota-specific $T$ cells in the skin offer protection against subsequent skin infection with Candida ${ }^{131}$. Thus, while 'antigen-free' survival of microbiota-specific $T$ cells remains an open question, it is clear that long-lived microbiota-specific T cells contribute to both immune-mediated protection and inflammatory disease.

It makes intuitive sense that $T$ cell responses against benign microorganisms that do not invade the host would be short-lived, since if they do not invade or secrete toxins that damage the host's cells, they are not generally a life-threatening problem. Thus, it might be a benefit to the host to make $T$ cell responses to the microbiota 'as required' to maintain plasticity and responsiveness in the face of constantly changing non-invasive microbiota. For example, microbiota-specific IgA producing B cells turnover in response to a changing microbiota, with new specificities against the dominant colonizers replacing the old but, in contrast, $\lg \mathrm{A}+$ plasma cells induced against enterotoxins show long-life ${ }^{166,167}$. The mechanism of the replacement of microbiota-specific clones is not clear, but it has been postulated that there is a ceiling on the niche available in the intestine for IgA producing $B$ cells and because they are much more numerous newly activated $B$ cells end up dominating these niches ${ }^{166}$. Interestingly no such ceiling has been detected for CD8 + memory T cells either in the secondary lymphoid tissues or the barrier sites such as the intestine ${ }^{168,169}$. Whether the intestine and skin can accommodate all microbiota-specific T cell clones or if there is competition and turnover in these populations remains unknown. As a corollary to the hypothesis that memory against benign, noninvasive members of the microbiota would be short-lived, memory functionality amongst $T$ cells at barrier surfaces would then be confined to $T$ cells that have been 'licensed' by cytokine signals derived from the immune response to invasive microorganisms (IFNy, IL-6, IL-12 and IL-18 etc.). Amongst microbiota-specific T cells activated at steady-state antigen-free memory has only demonstrated in Mucosa-Associated Invariant $T$ cells (MAIT) cells that inhabit barrier sites such as the skin and intestine ${ }^{170}$. MAIT cells are activated by riboflavin metabolites presented in the context of the of the MHC class I molecule MR1 ${ }^{171,172}$. In support of the 'licensing' hypothesis the riboflavin metabolites that activate MAIT cells are more commonly produced by more invasive 'pathogenic' bacteria, such as Enterobacteriaceae that will be associated with the induction of inflammatory cytokines ${ }^{170,173,174}$. 'Licensing' is also evident in the large differences in the transcriptome and metabolism of Th17 T cells responding to either the microbiota (SFB) or a toxin-producing pathogen (Citrobacter rodentium) ${ }^{175}$. Taken together, our knowledge of microbiota-specific $T$ cell responses is in its infancy because we have been restricted to studying a limited number of bacteria one at a time and lack a comprehensive view of the system. Hopefully, single-cell RNA sequencing combined with TCR specificity screening techniques might allow us to capture a more complete view of the antimicrobiota $\mathrm{T}$ cell immune response and how it is shaped over time. Further, we hope that a better understanding of the 'licensing signals' required for the formation of microbiota-specific memory $\mathrm{T}$ cells might allow us to limit these responses in the context of diseases of autoinflammation and activate them to form a population of heterologous Trm protection.

\section{CONCLUSION}

Tissue resident memory $\mathrm{T}$ cells reside long-term in host tissues and contribute to protection of that tissue from re-infection.
Tissue-resident memory $T$ cells are shaped by the tissue that they inhabit in way that is critical to their long-term survival and function. Barrier tissues are the most important sites patrolled by Trms and these tissues are colonized by tissue-specific microbiomes that are integral to the biology of the host tissue including the population of said tissue with Trms. Learning how to harness both microbiota-derived metabolites and antigens to shape the development of Trms is a potentially important area for future research as we have seen already that shifting the composition of the microbiota can be used to augment anti-tumor immunity. In the future, identification of the specific microorganisms and their metabolites that are capable of modulating Trms could lead to breakthroughs in the development of mucosal vaccines, tumor immunotherapy regimens, and treatments for chronic autoinflammatory disorders.

\section{REFERENCES}

1. McFall-Ngai, M. Adaptive immunity: Care for the community. Nature 445, 153 (2007).

2. Schenkel, J. M. \& Masopust, D. Tissue-resident memory T cells. Immunity 41 , 886-897 (2014).

3. Gebhardt, T., Palendira, U., Tscharke, D. C. \& Bedoui, S. Tissue-resident memory $\mathrm{T}$ cells in tissue homeostasis, persistent infection, and cancer surveillance. Immunol. Rev. 283, 54-76 (2018).

4. Schenkel, J. M., Fraser, K. A. \& Masopust, D. Cutting edge: resident memory CD8 T cells occupy frontline niches in secondary lymphoid organs. J. Immunol. 192, 2961-2964 (2014).

5. Nguyen, Q. P., Deng, T. Z., Witherden, D. A. \& Goldrath, A. W. Origins of CD4+ circulating and tissue-resident memory T-cells. Immunology 157, 3-12 (2019).

6. Amezcua Vesely, M. C. et al. Effector TH17 cells give rise to long-lived TRM cells that are essential for an immediate response against bacterial infection. Cell 178, 1176-1188.e15 (2019).

7. Shin, H. \& Iwasaki, A. A vaccine strategy that protects against genital herpes by establishing local memory T cells. Nature 491, 463-467 (2012).

8. Schenkel, J. M. et al. T cell memory. Resident memory CD8 T cells trigger protective innate and adaptive immune responses. Science 346, 98-101 (2014).

9. Weisel, N. M. et al. Comprehensive analyses of B-cell compartments across the human body reveal novel subsets and a gut-resident memory phenotype. Blood 136, 2774-2785 (2020)

10. Allie, S. R. et al. The establishment of resident memory B cells in the lung requires local antigen encounter. Nat. Immunol. 20, 97-108 (2019).

11. Allie, S. R. \& Randall, T. D. Resident memory B cells. Viral Immunol. 33, 282-293 (2020).

12. Lozupone, C. A., Stombaugh, J. I., Gordon, J. I., Jansson, J. K. \& Knight, R. Diversity, stability and resilience of the human gut microbiota. Nature 489, 220-230 (2012).

13. Burr, A. H. P., Bhattacharjee, A. \& Hand, T. W. Nutritional modulation of the microbiome and immune response. J. Immunol. 205, 1479-1487 (2020).

14. Wastyk, H. C. et al. Gut-microbiota-targeted diets modulate human immune status. Cell 184, 4137-4153.e14 (2021).

15. Hand, T. W., Vujkovic-Cvijin, I., Ridaura, V. K. \& Belkaid, Y. Linking the microbiota, chronic disease, and the immune system. Trends Endocrinol. Metab. 27, 831-843 (2016).

16. Costello, E. K. et al. Bacterial community variation in human body habitats across space and time. Science 326, 1694-1697 (2009).

17. Molloy, M. J. et al. Intraluminal containment of commensal outgrowth in the gut during infection-induced dysbiosis. Cell Host Microbe 14, 318-328 (2013).

18. Kalan, L. R. et al. Strain- and species-level variation in the microbiome of diabetic wounds is associated with clinical outcomes and therapeutic efficacy. Cell Host Microbe 25, 641-655.e5 (2019).

19. Lupp, C. et al. Host-mediated inflammation disrupts the intestinal microbiota and promotes the overgrowth of Enterobacteriaceae. Cell Host Microbe 2, 119-129 (2007).

20. Dethlefsen, L., Huse, S., Sogin, M. L. \& Relman, D. A. The pervasive effects of an antibiotic on the human gut microbiota, as revealed by deep $16 \mathrm{~S}$ rRNA sequencing. PLoS Biol. 6, e280 (2008).

21. Herndler-Brandstetter, D. et al. KLRG1+ Effector CD8+ T Cells Lose KLRG1, differentiate into all memory $\mathrm{T}$ cell lineages, and convey enhanced protective immunity. Immunity 48, 716-729.e8 (2018).

22. Mackay, L. K. et al. The developmental pathway for CD103(+)CD8+ tissueresident memory T cells of skin. Nat. Immunol. 14, 1294-1301 (2013). 
23. Behr, F. M., Chuwonpad, A., Stark, R. \& van Gisbergen, K. P. J. M. Armed and ready: Transcriptional regulation of tissue-resident memory CD8 T cells. Front. Immunol. 9, 1770 (2018)

24. Bankovich, A. J., Shiow, L. R. \& Cyster, J. G. CD69 suppresses sphingosine 1-phosophate receptor-1 (S1P1) function through interaction with membrane helix 4. J. Biol. Chem. 285, 22328-22337 (2010).

25. Dijkgraaf, F. E., Kok, L. \& Schumacher, T. N. M. Formation of tissue-resident CD8+ T-cell memory. Cold Spring Harb. Perspect. Biol. 13, (2021).

26. Mohammed, J. et al. Stromal cells control the epithelial residence of DCs and memory $T$ cells by regulated activation of TGF- $\beta$. Nat. Immunol. 17, 414-421 (2016).

27. Hirai, T. et al. Competition for active TGF $\beta$ cytokine allows for selective retention of antigen-specific tissue- resident memory $T$ cells in the epidermal niche. Immunity 54, 84-98.e5 (2021).

28. Zhang, N. \& Bevan, M. J. Transforming growth factor- $\beta$ signaling controls the formation and maintenance of gut-resident memory $\mathrm{T}$ cells by regulating migration and retention. Immunity 39, 687-696 (2013).

29. Nath, A. P. et al. Comparative analysis reveals a role for TGF- $\beta$ in shaping the residency-related transcriptional signature in tissue-resident memory CD8+ T cells. PLoS One 14, e0210495 (2019).

30. Mackay, L. K. et al. Hobit and Blimp1 instruct a universal transcriptional program of tissue residency in lymphocytes. Science 352, 459-463 (2016).

31. Adachi, T. et al. Hair follicle-derived IL-7 and IL-15 mediate skin-resident memory T cell homeostasis and lymphoma. Nat. Med. 21, 1272-1279 (2015).

32. Mazmanian, S. K., Liu, C. H., Tzianabos, A. O. \& Kasper, D. L. An immunomodulatory molecule of symbiotic bacteria directs maturation of the host immune system. Cell 122, 107-118 (2005).

33. Olszak, T. et al. Microbial exposure during early life has persistent effects on natural killer T cell function. Science 336, 489-493 (2012).

34. Ichinohe, $T$. et al. Microbiota regulates immune defense against respiratory tract influenza A virus infection. Proc. Natl Acad. Sci. USA 108, 5354-5359 (2011).

35. Abt, M. C. et al. Commensal bacteria calibrate the activation threshold of innate antiviral immunity. Immunity 37, 158-170 (2012).

36. Shaw, M. H., Kamada, N., Kim, Y.-G. \& Núñez, G. Microbiota-induced IL-1ß, but not IL-6, is critical for the development of steady-state TH17 cells in the intestine. J. Exp. Med 209, 251-258 (2012).

37. Hoshi, N. et al. MyD88 signalling in colonic mononuclear phagocytes drives colitis in IL-10-deficient mice. Nat. Commun. 3, 1120 (2012).

38. Clarke, T. B. et al. Recognition of peptidoglycan from the microbiota by Nod1 enhances systemic innate immunity. Nat. Med. 16, 228-231 (2010).

39. Tanaka, K., Sawamura, S., Satoh, T., Kobayashi, K. \& Noda, S. Role of the indigenous microbiota in maintaining the virus-specific CD8 memory $T$ cells in the lung of mice infected with murine cytomegalovirus. J. Immunol. 178, 5209-5216 (2007).

40. Becattini, S. et al. Enhancing mucosal immunity by transient microbiota depletion. Nat. Commun. 11, 4475 (2020).

41. Rosshart, S. P. et al. Laboratory mice born to wild mice have natural microbiota and model human immune responses. Science 365, (2019).

42. Ubeda, C. et al. Familial transmission rather than defective innate immunity shapes the distinct intestinal microbiota of TLR-deficient mice. J. Exp. Med. 209, 1445-1456 (2012)

43. Beura, L. K. et al. Normalizing the environment recapitulates adult human immune traits in laboratory mice. Nature 532, 512-516 (2016).

44. Rosshart, S. P. et al. Wild mouse gut microbiota promotes host fitness and improves disease resistance. Cell 171, 1015-1028.e13 (2017).

45. Lin, J.-D. et al. Rewilding nod 2 and atg1611 mutant mice uncovers genetic and environmental contributions to microbial responses and immune cell composition. Cell Host Microbe 27, 830-840.e4 (2020).

46. Abolins, S. et al. The comparative immunology of wild and laboratory mice, Mus musculus domesticus. Nat. Commun. 8, 14811 (2017).

47. Reese, T. A. et al. Sequential infection with common pathogens promotes human-like immune gene expression and altered vaccine response. Cell Host Microbe 19, 713-719 (2016).

48. Arpaia, N. et al. Metabolites produced by commensal bacteria promote peripheral regulatory T-cell generation. Nature 504, 451-455 (2013).

49. Smith, P. M. et al. The microbial metabolites, short-chain fatty acids, regulate colonic Treg cell homeostasis. Science 341, 569-573 (2013).

50. Furusawa, Y. et al. Commensal microbe-derived butyrate induces the differentiation of colonic regulatory T cells. Nature 504, 446-450 (2013).

51. Maslowski, K. M. et al. Regulation of inflammatory responses by gut microbiota and chemoattractant receptor GPR43. Nature 461, 1282-1286 (2009).

52. Trompette, A. et al. Dietary fiber confers protection against flu by shaping Ly6cpatrolling monocyte hematopoiesis and CD8+ T Cell metabolism. Immunity 48 , 992-1005.e8 (2018).
53. Kaech, S. M. \& Cui, W. Transcriptional control of effector and memory CD8+ T cell differentiation. Nat. Rev. Immunol. 12, 749-761 (2012).

54. Balmer, M. L. et al. Memory CD8(+) T cells require increased concentrations of acetate induced by stress for optimal function. Immunity 44, 1312-1324 (2016).

55. Bachem, A. et al. Microbiota-Derived Short-Chain Fatty Acids Promote the Memory Potential of Antigen-Activated CD8+ T Cells. Immunity 51, 285-297.e5 (2019).

56. Pearce, E. L., Poffenberger, M. C., Chang, C.-H. \& Jones, R. G. Fueling immunity: insights into metabolism and lymphocyte function. Science 342, 1242454 (2013).

57. Laidlaw, B. J. et al. Production of IL-10 by CD4(+) regulatory T cells during the resolution of infection promotes the maturation of memory CD8(+) T cells. Nat. Immunol. 16, 871-879 (2015).

58. Cui, W., Liu, Y., Weinstein, J. S., Craft, J. \& Kaech, S. M. An interleukin-21-interleukin-10-STAT3 pathway is critical for functional maturation of memory CD8+ T cells. Immunity 35, 792-805 (2011).

59. Grizotte-Lake, M. et al. Commensals suppress intestinal epithelial cell retinoic acid synthesis to regulate Interleukin-22 activity and prevent microbial dysbiosis. Immunity 49, 1103-1115.e6 (2018).

60. Woo et al. Commensal segmented filamentous bacteria-derived retinoic acid primes host defense to intestinal infection. Cell Host Microbe. https://doi.org/ 10.1016/j.chom.2021.09.010

61. Klebanoff, C. A. et al. Retinoic acid controls the homeostasis of pre-cDC-derived splenic and intestinal dendritic cells. J. Exp. Med. 210, 1961-1976 (2013)

62. Hall, J. A. et al. Essential role for retinoic acid in the promotion of CD4(+) T cell effector responses via retinoic acid receptor alpha. Immunity 34, 435-447 (2011).

63. Iwata, M. et al. Retinoic acid imprints gut-homing specificity on T cells. Immunity 21, 527-538 (2004).

64. Hammerschmidt, S. I. et al. Stromal mesenteric lymph node cells are essential for the generation of gut-homing T cells in vivo. J. Exp. Med. 205, 2483-2490 (2008).

65. Song, $X$. et al. Microbial bile acid metabolites modulate gut $R O R \gamma+$ regulatory $T$ cell homeostasis. Nature 577, 410-415 (2020).

66. Chen, M. L. et al. CAR directs T cell adaptation to bile acids in the small intestine. Nature 593, 147-151 (2021).

67. Cao, W. et al. The xenobiotic transporter mdr1 enforces $\mathrm{T}$ cell homeostasis in the presence of intestinal bile acids. Immunity 47, 1182-1196.e10 (2017).

68. Shalapour, S. et al. Commensal microflora and interferon-gamma promote steady-state interleukin-7 production in vivo. Eur. J. Immunol. 40, 2391-2400 (2010).

69. Oshima, S. et al. Interferon regulatory factor 1 (IRF-1) and IRF-2 distinctively upregulate gene expression and production of interleukin-7 in human intestinal epithelial cells. Mol. Cell. Biol. 24, 6298-6310 (2004).

70. Schenkel, J. M. et al. IL-15-independent maintenance of tissue-resident and boosted effector memory CD8 T cells. J. Immunol. 196, 3920-3926 (2016).

71. Caminero, A., Meisel, M., Jabri, B. \& Verdu, E. F. Mechanisms by which gut microorganisms influence food sensitivities. Nat. Rev. Gastroenterol. Hepatol. 16, 7-18 (2019).

72. Gevers, D. et al. The treatment-naive microbiome in new-onset Crohn's disease. Cell Host Microbe 15, 382-392 (2014).

73. Jiang, W. et al. Recognition of gut microbiota by NOD2 is essential for the homeostasis of intestinal intraepithelial lymphocytes. J. Exp. Med. 210, 2465-2476 (2013)

74. Nizard, M. et al. Induction of resident memory T cells enhances the efficacy of cancer vaccine. Nat. Commun. 8, 15221 (2017).

75. Milner, J. J. et al. Runx 3 programs $C D 8+T$ cell residency in non-lymphoid tissues and tumours. Nature 552, 253-257 (2017).

76. Malik, B. T. et al. Resident memory T cells in the skin mediate durable immunity to melanoma. Sci. Immunol. 2, (2017).

77. Enamorado, M. et al. Enhanced anti-tumour immunity requires the interplay between resident and circulating memory CD8+ T cells. Nat. Commun. 8, 16073 (2017).

78. Savas, P. et al. Single-cell profiling of breast cancer T cells reveals a tissueresident memory subset associated with improved prognosis. Nat. Med. 24, 986-993 (2018).

79. Duhen, $T$. et al. Co-expression of CD39 and CD103 identifies tumor-reactive CD8 T cells in human solid tumors. Nat. Commun. 9, 2724 (2018).

80. Ganesan, A.-P. et al. Tissue-resident memory features are linked to the magnitude of cytotoxic T cell responses in human lung cancer. Nat. Immunol. 18, 940-950 (2017).

81. McQuade, J. L., Daniel, C. R., Helmink, B. A. \& Wargo, J. A. Modulating the microbiome to improve therapeutic response in cancer. Lancet Oncol. 20, e77-e91 (2019).

82. Gopalakrishnan, V. et al. Gut microbiome modulates response to anti-PD-1 immunotherapy in melanoma patients. Science 359, 97-103 (2018). 
83. Routy, B. et al. Gut microbiome influences efficacy of PD-1-based immunotherapy against epithelial tumors. Science 359, 91-97 (2018).

84. Matson, V. et al. The commensal microbiome is associated with anti-PD-1 efficacy in metastatic melanoma patients. Science 359, 104-108 (2018).

85. Tanoue, T. et al. A defined commensal consortium elicits CD8 T cells and anticancer immunity. Nature 565, 600-605 (2019).

86. Mager, L. F. et al. Microbiome-derived inosine modulates response to checkpoint inhibitor immunotherapy. Science 369, 1481-1489 (2020).

87. Scheper, W. et al. Low and variable tumor reactivity of the intratumoral TCR repertoire in human cancers. Nat. Med. 25, 89-94 (2019).

88. Simoni, Y. et al. Bystander CD8+ T cells are abundant and phenotypically distinct in human tumour infiltrates. Nature 557, 575-579 (2018).

89. Danahy, D. B., Berton, R. R. \& Badovinac, V. P. Cutting edge: Antitumor immunity by pathogen-specific CD8 $T$ cells in the absence of cognate antigen recognition. J. Immunol. 204, 1431-1435 (2020).

90. Rosato, P. C. et al. Virus-specific memory T cells populate tumors and can be repurposed for tumor immunotherapy. Nat. Commun. 10, 567 (2019).

91. Overacre-Delgoffe AE, Bumgarner HJ, Cillo AR, Burr AHP, Tometich JT, Bhattacharjee $A$, et al. Microbiota-specific $T$ follicular helper cells drive tertiary lymphoid structures and anti-tumor immunity against colorectal cancer. Immunity 54, 2812-2824.e4 (2021).

92. Yu, A. I. et al. Gut microbiota modulate CD8 T cell responses to influence colitisassociated tumorigenesis. Cell Rep. 31, 107471 (2020).

93. Xing, $C$. et al. Microbiota regulate innate immune signaling and protective immunity against cancer. Cell Host Microbe https://doi.org/10.1016/j. chom.2021.03.016 (2021).

94. Bullman, S. et al. Analysis of Fusobacterium persistence and antibiotic response in colorectal cancer. Science 358, 1443-1448 (2017).

95. Dang, L. H., Bettegowda, C., Huso, D. L., Kinzler, K. W. \& Vogelstein, B. Combination bacteriolytic therapy for the treatment of experimental tumors. Proc. Natl. Acad. Sci. USA 98, 15155-15160 (2001).

96. Yazawa, K., Fujimori, M., Amano, J., Kano, Y. \& Taniguchi, S. Bifidobacterium longum as a delivery system for cancer gene therapy: Selective localization and growth in hypoxic tumors. Cancer Gene Ther. 7, 269-274 (2000).

97. Nejman, D. et al. The human tumor microbiome is composed of tumor typespecific intracellular bacteria. Science 368, 973-980 (2020).

98. Xuan, C. et al. Microbial dysbiosis is associated with human breast cancer. PLoS One 9, e83744 (2014).

99. Peters, B. A. et al. The microbiome in lung cancer tissue and recurrence-free survival. Cancer Epidemiol. Biomark. Prev. 28, 731-740 (2019).

100. $\mathrm{Ma}, \mathrm{C}$. et al. Gut microbiome-mediated bile acid metabolism regulates liver cancer via NKT cells. Science 360, (2018).

101. Miyazaki, K. et al. Colonic epithelial cells express specific ligands for mucosal macrophage immunosuppressive receptors siglec-7 and -9. J. Immunol. 188, 4690-4700 (2012).

102. Sun, J. \& Kato, I. Gut microbiota, inflammation and colorectal cancer. Genes Dis. 3, 130-143 (2016).

103. Zeng, H., Lazarova, D. L. \& Bordonaro, M. Mechanisms linking dietary fiber, gut microbiota and colon cancer prevention. World J. Gastrointest. Oncol. 6, 41-51 (2014).

104. Farrell, J. J. et al. Variations of oral microbiota are associated with pancreatic diseases including pancreatic cancer. Gut 61, 582-588 (2012).

105. Arthur, J. C. et al. Intestinal inflammation targets cancer-inducing activity of the microbiota. Science 338, 120-123 (2012).

106. Dejea, C. M. et al. Patients with familial adenomatous polyposis harbor colonic biofilms containing tumorigenic bacteria. Science 359, 592-597 (2018).

107. Kostic, A. D. et al. Fusobacterium nucleatum potentiates intestinal tumorigenesis and modulates the tumor-immune microenvironment. Cell Host Microbe 14, 207-215 (2013).

108. Honda, K. \& Littman, D. R. The microbiota in adaptive immune homeostasis and disease. Nature 535, 75-84 (2016)

109. Kumar, P. et al. Intestinal Interleukin-17 receptor signaling mediates reciprocal control of the gut microbiota and autoimmune inflammation. Immunity 44, 659-671 (2016).

110. Bos, N. A., Jiang, H. Q. \& Cebra, J. J. T cell control of the gut IgA response against commensal bacteria. Gut 48, 762-764 (2001).

111. Atarashi, K. et al. Th17 cell induction by adhesion of microbes to intestinal epithelial cells. Cell 163, 367-380 (2015).

112. Ivanov, I. I. et al. Induction of intestinal Th17 cells by segmented filamentous bacteria. Cell 139, 485-498 (2009).

113. Chiaranunt, P., Tometich, J. T., Ji, J. \& Hand, T. W. T cell proliferation and colitis are initiated by defined intestinal microbes. J. Immunol. 201, 243-250 (2018).

114. Herp, S. et al. Mucispirillum schaedleri antagonizes salmonella virulence to protect mice against colitis. Cell Host Microbe 25, 681-694.e8 (2019).
115. Melo-Gonzalez, F. et al. Antigen-presenting ILC3 regulate T cell-dependent IgA responses to colonic mucosal bacteria. J. Exp. Med. 216, 728-742 (2019).

116. Chai, J. N. et al. Helicobacter species are potent drivers of colonic T cell responses in homeostasis and inflammation. Sci. Immunol. 2, (2017).

117. $\mathrm{Xu}, \mathrm{M}$. et al. c-MAF-dependent regulatory $\mathrm{T}$ cells mediate immunological tolerance to a gut pathobiont. Nature 554, 373-377 (2018).

118. Wegorzewska, M. M. et al. Diet modulates colonic $T$ cell responses by regulating the expression of a Bacteroides thetaiotaomicron antigen. Sci. Immunol. 4, (2019).

119. Hickey, C. A. et al. Colitogenic bacteroides thetaiotaomicron antigens access host immune cells in a sulfatase-dependent manner via outer membrane vesicles. Cell Host Microbe 17, 672-680 (2015).

120. Hand, T. W. et al. Acute gastrointestinal infection induces long-lived microbiotaspecific T cell responses. Science 337, 1553-1556 (2012).

121. Esterházy, D. et al. Compartmentalized gut lymph node drainage dictates adaptive immune responses. Nature 569, 126-130 (2019).

122. Houston, S. A. et al. The lymph nodes draining the small intestine and colon are anatomically separate and immunologically distinct. Mucosal. Immunol. 9, 468-478 (2016).

123. Gaboriau-Routhiau, V. et al. The key role of segmented filamentous bacteria in the coordinated maturation of gut helper $\mathrm{T}$ cell responses. Immunity 31, 677-689 (2009).

124. Ansaldo, E. et al. Akkermansia muciniphila induces intestinal adaptive immune responses during homeostasis. Science 364, 1179-1184 (2019).

125. Howitt, M. R. et al. Tuft cells, taste-chemosensory cells, orchestrate parasite type 2 immunity in the gut. Science 351, 1329-1333 (2016).

126. Chudnovskiy, A. et al. Host-protozoan interactions protect from mucosal infections through activation of the inflammasome. Cell 167, 444-456.e14 (2016).

127. Escalante, N. K. et al. The common mouse protozoa Tritrichomonas muris alters mucosal T cell homeostasis and colitis susceptibility. J. Exp. Med 213, 2841-2850 (2016).

128. Hebbandi Nanjundappa, R. et al. A gut microbial mimic that hijacks diabetogenic autoreactivity to suppress colitis. Cell 171, 655-667.e17 (2017).

129. Fluckiger, A. et al. Cross-reactivity between tumor MHC class I-restricted antigens and an enterococcal bacteriophage. Science 369, 936-942 (2020).

130. Corridoni, D. et al. Single-cell atlas of colonic CD8+ T cells in ulcerative colitis. Nat. Med. 26, 1480-1490 (2020).

131. Naik, S. et al. Commensal-dendritic-cell interaction specifies a unique protective skin immune signature. Nature 520, 104-108 (2015).

132. Scharschmidt, T. C. et al. A wave of regulatory T cells into neonatal skin mediates tolerance to commensal microbes. Immunity 43, 1011-1021 (2015).

133. Linehan, J. L. et al. Non-classical immunity controls microbiota impact on skin immunity and tissue repair. Cell 172, 784-796.e18 (2018).

134. Harrison, O. J. et al. Commensal-specific T cell plasticity promotes rapid tissue adaptation to injury. Science 363, (2019).

135. Nosbaum, A. et al. Cutting edge: Regulatory T cells facilitate cutaneous wound healing. J. Immunol. 196, 2010-2014 (2016).

136. Grice, E. A. et al. Topographical and temporal diversity of the human skin microbiome. Science 324, 1190-1192 (2009).

137. Gajer, P. et al. Temporal dynamics of the human vaginal microbiota. Sci. Transl. Med. 4, 132ra52 (2012).

138. Devkota, S. et al. Dietary-fat-induced taurocholic acid promotes pathobiont expansion and colitis in II10-/- mice. Nature 487, 104-108 (2012).

139. Mu, Q., Tavella, V. J. \& Luo, X. M. Role of Lactobacillus reuteri in human health and diseases. Front. Microbiol. 9, 757 (2018).

140. Verma, A. H. et al. Oral epithelial cells orchestrate innate type 17 responses to Candida albicans through the virulence factor candidalysin. Sci. Immunol. 2, (2017).

141. Dutzan, N. et al. On-going mechanical damage from mastication drives homeostatic Th17 cell responses at the oral barrier. Immunity 46, 133-147 (2017).

142. Perez-Muñoz, M. E., Arrieta, M.-C., Ramer-Tait, A. E. \& Walter, J. A critical assessment of the "sterile womb" and "in utero colonization" hypotheses: implications for research on the pioneer infant microbiome. Microbiome 5, 48 (2017).

143. Mishra, A. et al. Microbial exposure during early human development primes fetal immune cells. Cell 184, 3394-3409.e20 (2021).

144. Rackaityte, E. et al. Viable bacterial colonization is highly limited in the human intestine in utero. Nat. Med. 26, 599-607 (2020).

145. Stras, S. F. et al. Maturation of the human intestinal immune system occurs early in fetal development. Dev. Cell 51, 357-373.e5 (2019).

146. Lim, A. I. et al. Prenatal maternal infection promotes tissue-specific immunity and inflammation in offspring. Science 373, (2021).

147. Gopalakrishna, K. P. \& Hand, T. W. Influence of maternal milk on the neonatal intestinal microbiome. Nutrients 12, (2020). 
148. Torow, N. et al. Active suppression of intestinal CD4(+)TCRaß(+) T-lymphocyte maturation during the postnatal period. Nat. Commun. 6, 7725 (2015).

149. Koch, M. A. et al. Maternal igg and iga antibodies dampen mucosal T helper cell responses in early life. Cell 165, 827-841 (2016).

150. Kim, K. S. et al. Dietary antigens limit mucosal immunity by inducing regulatory T cells in the small intestine. Science 351, 858-863 (2016).

151. Sefik, E. et al. MUCOSAL IMMUNOLOGY. Individual intestinal symbionts induce a distinct population of ROR ${ }^{+}$regulatory T cells. Science 349, 993-997 (2015).

152. Ohnmacht, C. et al. MUCOSAL IMMUNOLOGY. The microbiota regulates type 2 immunity through RORyt ${ }^{+}$T cells. Science 349, 989-993 (2015).

153. Geva-Zatorsky, N. et al. Mining the human gut microbiota for immunomodulatory organisms. Cell 168, 928-943.e11 (2017).

154. Al Nabhani, Z. et al. A weaning reaction to microbiota is required for resistance to immunopathologies in the adult. Immunity 50, 1276-1288.e5 (2019).

155. Ramanan, D. et al. An immunologic mode of multigenerational transmission governs a gut treg setpoint. Cell 181, 1276-1290.e13 (2020).

156. Huus, K. E. et al. Immunoglobulin recognition of fecal bacteria in stunted and non-stunted children: Findings from the Afribiota study. Microbiome 8, 113 (2020).

157. Kau, A. L. et al. Functional characterization of IgA-targeted bacterial taxa from undernourished Malawian children that produce diet-dependent enteropathy. Sci. Transl. Med. 7, 276 ra24 (2015).

158. Bhattacharjee, A. et al. Environmental enteric dysfunction induces regulatory $T$ cells that inhibit local CD4 $+\mathrm{T}$ cell responses and impair oral vaccine efficacy. Immunity 54, 1745-1757.e7 (2021).

159. Pepper, M. et al. Different routes of bacterial infection induce long-lived TH1 memory cells and short-lived TH17 cells. Nat. Immunol. 11, 83-89 (2010).

160. Murali-Krishna, K. et al. Counting antigen-specific CD8 T cells: A reevaluation of bystander activation during viral infection. Immunity 8, 177-187 (1998).

161. Hegazy, A. N. et al. Circulating and tissue-resident CD4+ T cells with reactivity to intestinal microbiota are abundant in healthy individuals and function is altered during inflammation. Gastroenterology 153, 1320-1337.e16 (2017).

162. Nemoto, Y. et al. Long-lived colitogenic CD4+ memory $T$ cells residing outside the intestine participate in the perpetuation of chronic colitis. J. Immunol. 183, 5059-5068 (2009).

163. Smillie, C. S. et al. Intra- and inter-cellular rewiring of the human colon during ulcerative colitis. Cell 178, 714-730.e22 (2019).

164. Noble, A. et al. Deficient resident memory $T$ cell and CD8 T cell response to commensals in inflammatory bowel disease. J. Crohns Colitis 14, 525-537 (2020).

165. Khairallah, C. et al. A blend of broadly-reactive and pathogen-selected $\mathrm{V} \gamma 4 \mathrm{~V} \delta 1 \mathrm{~T}$ cell receptors confer broad bacterial reactivity of resident memory $\gamma \delta \mathrm{T}$ cells. Mucosal Immunol. https://doi.org/10.1038/s41385-021-00447-x (2021).

166. Hapfelmeier, S. et al. Reversible microbial colonization of germ-free mice reveals the dynamics of IgA immune responses. Science 328, 1705-1709 (2010).
167. Bemark, M. et al. Limited clonal relatedness between gut IgA plasma cells and memory B cells after oral immunization. Nat. Commun. 7, 12698 (2016).

168. Wijeyesinghe, $\mathrm{S}$. et al. Expansible residence decentralizes immune homeostasis. Nature 592, 457-462 (2021).

169. Vezys, V. et al. Memory CD8 T-cell compartment grows in size with immunological experience. Nature 457, 196-199 (2009).

170. Constantinides, M. G. et al. MAIT cells are imprinted by the microbiota in early life and promote tissue repair. Science 366, (2019).

171. Kjer-Nielsen, L. et al. MR1 presents microbial vitamin B metabolites to MAIT cells. Nature 491, 717-723 (2012).

172. Treiner, E. et al. Selection of evolutionarily conserved mucosal-associated invariant T cells by MR1. Nature 422, 164-169 (2003).

173. Nel, I., Bertrand, L., Toubal, A. \& Lehuen, A. MAIT cells, guardians of skin and mucosa? Mucosal Immunol. 14, 803-814 (2021).

174. Lupp, C. et al. Host-mediated inflammation disrupts the intestinal microbiota and promotes the overgrowth of Enterobacteriaceae. Cell Host Microbe 2, 204 (2007).

175. Omenetti, S. et al. The intestine harbors functionally distinct homeostatic tissueresident and inflammatory Th17 cells. Immunity 51, 77-89.e6 (2019).

\section{ACKNOWLEDGEMENTS}

We apologize that not all papers in this expanding field could be discussed and referenced. AEO is supported by a Damon Runyon Cancer Research Foundation Postdoctoral Fellowship (2360-19 to A.O.D.). This work was supported by grants from the NIH (R21Al142051, R21CA249074; TWH) and a Burroughs Wellcome Foundation Investigator in the Pathogenesis of Infectious Disease award (TWH). We would like to thank the members of the Hand lab for helpful discussions.

\section{COMPETING INTERESTS}

The authors declare no competing interests.

\section{ADDITIONAL INFORMATION}

Correspondence and requests for materials should be addressed to Timothy $\mathrm{W}$. Hand.

Reprints and permission information is available at http://www.nature.com/ reprints

Publisher's note Springer Nature remains neutral with regard to jurisdictional claims in published maps and institutional affiliations. 